\title{
Understanding and Research of Language Unities as Way of Removal of Barriers of Cross-cultural Communication
}

\author{
Vladimir Mikhailov \\ Institute of Languages and Cultures of Leo Tolstoy \\ Moscow, Russia \\ E-mail: myhailovvv@mail.ru
}

\begin{abstract}
This work considers and offers various methods of removing barriers in the cross-cultural communication in the sphere of language based on the development of theories of language origin and development, and the technologies of their studying and translation, not really known in masses. The problems of a number of uncommon methods of work with information in general are raised.
\end{abstract}

Keywords—philosophy of language and culture; removal of language restrictions and barriers

\section{INTRODUCTION}

Any communication and any communication happen in this or that language which is for it the tool, means and the carrying-out environment. If this carrying-out environment is non-uniform, and means are various, then communication is difficult. On the other hand, maintaining the language identity and sovereignty is the most important element of maintaining the ethnocultural originality and freedom. As in this regard one French writer witty noticed: "My fatherland is not France, and French". The author is in many respects solidary with this position as the person, especially today, can move rather easily worldwide, changing the territory of the accommodation and even to change the state accessory (nationality, the status of the tax resident or employee of this or that corporation). It does language, along with genetics the most important sign of ethnocultural identification and identity of the person.

Besides, the cash main international language (today Anglo-American) absolutely not necessarily is the best in all the parameters, so, can promote decrease in intelligence, accuracy of expression of a thought, translation from other languages and narrowing of an outlook. The similar situation creates conditions for creation, but not cash withdrawal of language restrictions, infringements of the rights and freedoms of both the certain person, and the people or other communities and groups.

There is no language equality really as it approves politically correct legal formation of myths. How to solve this problem?

\section{WAYS AND METHODS OF REMOVAL OF LANGUAGE RESTRICTIONS}

There are several ways. It and awareness of global language unity of mankind when all verbal written languages seem not as the conglomerate of untied parts, but as a whole in which separate languages smoothly pass each other that most well considerably on examples of close languages, for example, Slavic, Romance, dialects in China or Germany (V. D. Osipov concept). Or languages seem coming from one (or even several) roots (P. A. Lukashevich concept and similar to it) [1] [2].

Another approach is an allocation of some basic languages making a system underlying cause of all others (the concept of the Russian and Arab languages as "the system languages of a brain" (more precisely consciousnesses) N. N. Vashkevich) [3]. Other way is a search of methods of effective converting (translation) of values of one languages in others: N. N. Vashkevich's method on mutual converting of meanings of the Arab and Russian words, S. A. Dubov's method on decoding of meanings of words of the Indo-European languages on sound and alphabetic matrixes of the Glagolitic alphabet, passing their traditional translation. The third way offers the judgment and use of nonverbal languages of communication: a mimicry and gestures, emotions, images, smells, tastes, melodies which often differ at the different people not so strongly (except for language of a mimicry and gestures) as verbal written languages and are simpler in studying. By the way, identification by sign "others" often happens on these signs, but not on language as potential "spy" will learn language first of all. The fourth way presents the updating and use the extra sensory ways of communication (telepathy, etc.) also being outside usual language restrictions.

So, as we see, ways of removal of linguistic barriers of cross-cultural communication not so are not enough However, they are used today poorly as in masses the standardized thinking, "logic of the TV" and other similar cognitive defects prevail.

However, on the other hand, literatures, the ideas and more concrete developments on nontrivial linguistics there is 
a lot of now, but they often are not "scientific" in classical sense (or do not fit into a framework of the dominating scientific paradigms), and, therefore, is torn away by an official education system, the government and corporate officials and the mass of consumers operated by them.

The so-called "scientific linguistics" works by the principles of political strategy science of the British political scientist F. Bacon who is written down in Russia in great philosophers and science theorists and "profane-professorial" science Andrei I. Fursov. The essence of political strategy science is that the scientific result is created as the user's guide to operation of an object, but not true knowledge of it. Fursov formulated in the articles and books the basic principles and methods of new science with which it would be useful to get acquainted for adequate assessment of parascientific linguistics in the spirit of P. A. Lukashevich or N. N. Vashkevich [4]. The same who does not wish to penetrate into science problems can be advised, simply to study and put into practice useful linguistic theories and technologies of studying of languages and the translation, being guided by an intuition and their real practical effect.

Regular practice of work with the replying literature, for example, the book by V. D. Osipov "Uniform language of mankind" naturally will adjust consciousness on thinking in the corresponding foreshortening and will create basic skills of work with information.

It is also useful to create some own methods, methods and mechanisms of cross-cultural and translanguage communication as required, instead of copying of others knowledge and experience. Such approach is justified by the fact that any others experience carries the character which is not personified for his consumer, that is does not correspond to his knowledge, experience, abilities and a course of life, and therefore demands personification, that is processing and adaptation to the requirements.

\section{Stages OF WORK ON REMOVAl OF LANGUAGE RESTRICTIONS}

So, the first stage of removal of unnecessary barriers of cross-cultural communication is exactly awareness of basic language unities of various groups of mankind. For this purpose, it is necessary to refuse from the Euro-centric (and especially the American-centric) scientific and informative standards and trivial thinking.

The second stage is a finding and studying of the corresponding information materials. Let's say development of works of N. N. Vashkevich. At the same time the main data array of materials can be outside semi-official science and education. If the pupil acts like the religious dogmatic person, being guided only on "blagomyslenny" (J. Orwell) materials of scientific and materialistic dogma, then in this case he will not achieve success.

The third stage presents the use of the mastered material in practice in the course of the learning of foreign languages and communication with representatives of other culture.
So, knowledge of works of N. N. Vashkevich will deeply help the reader to penetrate in particular Arabic and its interrelation with Russian that it, undoubtedly, will make it much more competent of the sphere of Arab-Islamic culture. Interest in Arabic and Islamic culture respectively will help it with setting of contacts and communications with her representatives on the basis of common interests.

In contacts with Europeans, first of all with Slavs, for Russians work with the dictionary of Indo-European words of J.A. Kesler [5] or P.A. Lukashevich's works can play a similar role.

\section{CONCLUSION}

Apparently, in article the methodology of removal of language restrictions as one of barriers of cross-cultural communication and stages (technology) of its application is given. It demonstrates that for the problem put in introduction several ways of its decision are offered. In more detail this material is presented in the enclosed literature.

\section{REFERENCES}

[1] V. D. Osipov, Uniform language of mankind. M.: Piligrim-Press, 2003, 320 p.

[2] P. A. Lukashevich, Charomutiye, or the sacred language of magicians, magicians and priests opened by Platon Lukashevich. - M.: White Alvah, 2008, 144 p.

[3] N. N. Vashkevich, System languages of a brain. M., 1998, 400 p.

[4] A. I. Fursov, Russia on a threshold of the new world. Cold east wind2. M.: Book world, 2016, 384 p.

[5] J. A. Kesler, Alphabet and Russian-European dictionary. M.: Kraft + publishing house, 2001, $340 \mathrm{p}$. 